\title{
Later hunter-gatherers in southern China, 18 000-3000 BC
}

\section{Zhang $\mathrm{Chi}^{1}{ }^{2}$ Hsiao-chun Hung ${ }^{2}$}

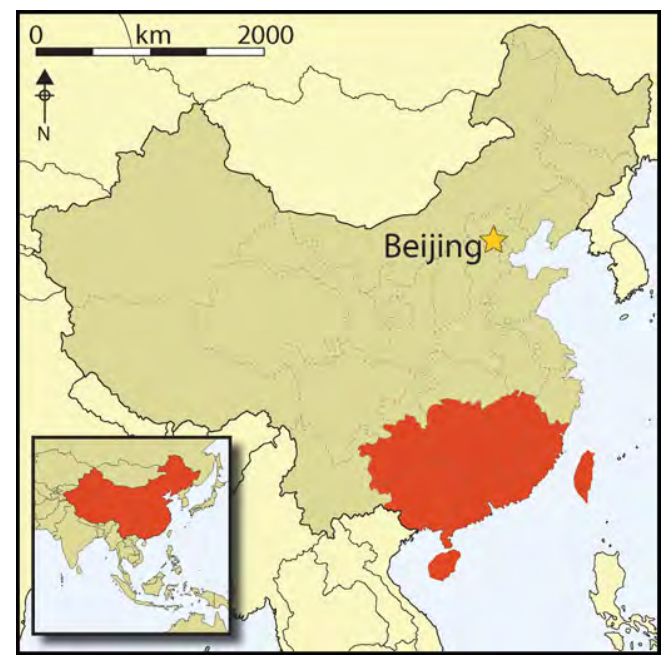

The authors present new research on social and economic developments in southern China in the Early Holocene, ninth to fifth millennia BC. The 'Neolithic package' doesn't really work for this fascinating chapter of the human experience, where pottery, social aggregation, animal domestication and rice cultivation all arrive at different places and times. The authors define the role of the 'potteryusing foragers', sophisticated hunter-gatherers who left shell or fish middens in caves and dunes. These colonising non-farmers shared numerous cultural attributes with rice cultivators on the Yangtze, their parallel contemporaries over more than 5000 years. Some agriculturalists became hunter-foragers in turn when they expanded onto less fertile soils. No simple linear transition then, but the practice of ingenious strategies, adaptations and links in a big varied land.

Keywords: southern China, northern Vietnam, Neolithic transition, hunter-gatherers, early farmers, rice cultivation

\section{Introduction}

Chinese archaeologists refer variously to the period from the Late Pleistocene into the Early Holocene in southern China as Mesolithic, Post-Palaeolithic, Palaeolithic to Neolithic transition, or Early Neolithic (Zhang, C. 2000), where 'Neolithic' often means the arrival of pottery. But the Neolithic transition in East Asia had many components, separated in time and space. The earliest pottery in the world comes from the general region of East Asia—particularly Japan, Siberia and southern China—commencing about 20000 years ago (e.g. Lu, T.L-D. 1999; Zhang, C. 1999; Yasuda 2002; Boaretto et al. 2009) but does not imply agriculture. The normal assumption by East Asian archaeologists is that this pottery was made by forest hunter-gatherers (Yasuda 2002). About 11000 years later, initial

1 School of Archaeology and Museology, Peking University, Beijing, China

2 Department of Archaeology and Natural History, School of Culture, History and Language and School of Archaeology and Anthropology, The Australian National University, Canberra, ACT 0200, Australia (Email: hsiao-chun.hung@anu.edu.au) 
pre-domestication rice cultivation began in the region between the Yellow and Huai rivers (Zhang, C. 2011), and perhaps also in the Middle Yangtze Valley at c. 7000-6000 cal BC (e.g. Crawford \& Chen 1998; Yan 2002; Yasuda 2002; Bellwood 2005: 111; Zhang \& Hung 2008; Fuller et al. 2009).

Between 7000 and $2100 \mathrm{BC}$, some hunter-gatherer groups co-existed with early rice cultivators in the Middle and Lower Yangtze Valley, and a variety of mixed economies co-existed in southern China (Table 1). Three types of likely subsistence strategy may be defined: Pleistocene hunting-gathering, documented mostly in caves; more complex hunting-gathering in the Terminal Pleistocene and Early Holocene, in both caves and open settlements, with pottery and cemeteries; and the developing farming of food during the Middle Holocene. These three modes of subsistence were not exclusive, and each was associated with identifiable cultural characteristics that appeared with different chronologies, in different locations, in southern China.

In a previous study, we proposed that rice cultivation was introduced into southern China and Southeast Asia from the Middle and Lower Yangtze Valley through population movement around 3000-2000 BC, via separate coastal and inland routes (Zhang \& Hung 2010). In this paper we provide a social context for this innovation, focusing attention on the indigenous hunter-gatherer groups in China south of the Yangtze, and in particular exploring the nature of their economies before the introduction of rice-that is in the period between 18000 and 3000 BC (all carbon dates are calibrated unless otherwise noted).

\section{Sources}

The evidence comes predominantly from middens in caves (Figure 1) and open sites. The principal deposits and their cultural designations (see Figure 2 and Table 1) are the Dingsishan and Da But shell middens in Guangxi and northern Vietnam (Zone H), Gaomiao shell middens in the Middle Yuanshui Valley (Zone B), Chengbeixi-Daxi-Yuxiping deposits with dense fish bones in Xia-Jiang (the Three Gorges and western Hubei) (Zone Gh, within Zone G), Xiantouling sand dune sites in the Zhujiang (Pearl River) delta of Guangdong (Zone C), Keqiutou, Fuguodun (Zone D) and Dabenkeng (Zone F) shell middens along the south-eastern coasts of Guangdong, Fujian and northern Vietnam, together with Taiwan.

None of these sites has so far yielded any evidence for farming, but all have produced large numbers of pottery sherds and edge-ground stone tools, and the open sites indicate settlements with well-defined domestic, industrial and perhaps ritual areas. The task is to discover the possible role that these continuing hunter-gatherers played in subsequent cultural and population developments in Middle Holocene southern China.

\section{Terminal Pleistocene cave sites in southern China (Figure 1)}

Cave sites with large quantities of shell midden are distributed north and south of the Nanling Mountains. Important excavated caves include Xianrendong (Figure 1, no. 1; Figures 3 \& 4) and Diaotonghuan in Wannian (Jiangxi); Huangyandong in Fengkai, Dushizai in Yangchun, Niulandong in Yingde (Guangdong); Luobidong in Sanya (Hainan); Yuchanyan in Dao

(C) Antiquity Publications Ltd. 
Table 1. Chronological contexts of southern Chinese Neolithic cultures, both of farmers and of complex hunter-gatherers (the latter in italics). See also Figures $1 \& 2$.

\begin{tabular}{|c|c|c|c|c|c|c|c|c|c|c|c|}
\hline \multicolumn{2}{|l|}{ Region } & \multicolumn{6}{|c|}{ Yangtze alluvial plain } & \multicolumn{4}{|c|}{ South of the Nanling Mountains } \\
\hline \multirow[t]{2}{*}{ Age } & \multirow[t]{2}{*}{ Phase } & \multicolumn{2}{|l|}{$\begin{array}{l}\text { Hubei \& } \\
\quad \text { Xia-Jiang }\end{array}$} & \multirow{2}{*}{$\begin{array}{l}\text { Dongting } \\
\text { Lake } \\
\text { region } \\
\text { Dongting } \\
\text { Lake } \\
\text { plain } \\
\end{array}$} & \multirow{2}{*}{$\begin{array}{l}\text { Southern } \\
\text { Hunan } \\
\text { Yuanshui } \\
\text { River } \\
\text { region } \\
\end{array}$} & \multirow{2}{*}{$\begin{array}{l}\text { Gan-Bo region } \\
\text { Gan Valley } \\
\text { Poyang-Lake } \\
\text { plain }\end{array}$} & \multirow[t]{2}{*}{ Jiang-Zhe region } & \multirow[t]{2}{*}{ Guangxi } & \multirow[t]{2}{*}{ Guangdong } & \multirow[t]{2}{*}{ Fujian } & \multirow[t]{2}{*}{ Taiwan } \\
\hline & & $\begin{array}{l}\text { Xia-Jiang } \\
\text { region: Three } \\
\text { Gorges }\end{array}$ & Hubei region & & & & & & & & \\
\hline \multirow[t]{2}{*}{$\begin{array}{l}18000-7000 \\
\text { BC }\end{array}$} & $\begin{array}{l}\text { Late Palaeolithic } \\
\text { to Early } \\
\text { Neolithic }\end{array}$ & & & & & $\begin{array}{l}\text { Xianrendong } \mathcal{G} \\
\text { Diao- } \\
\text { tonghuan } \\
\text { caves }\end{array}$ & & $\begin{array}{l}\text { Dayan, } \\
\text { Miaoyan \& } \\
\text { Zengpiyan } \\
\text { caves }\end{array}$ & & & \\
\hline & & & & $\begin{array}{c}\text { Yuchanyan } \\
\text { Cave }\end{array}$ & & & & & $\begin{array}{l}\text { Niulandong } \\
\text { Cave }\end{array}$ & & \\
\hline \multirow[t]{2}{*}{$7000-5000 \mathrm{BC}$} & $\begin{array}{l}\text { Middle } \\
\text { Neolithic }\end{array}$ & & $\begin{array}{l}\text { Pengtoushan } \\
\text { culture }\end{array}$ & $\begin{array}{l}\text { Pengtoushan } \\
\text { culture }\end{array}$ & & & $\begin{array}{l}\text { Shangshan culture } \\
\text { Xiaohuangshan- } \\
\text { Kuahuqiao } \\
\text { culture }\end{array}$ & $\begin{array}{l}\text { Dingsishan } \\
\text { culture }\end{array}$ & & & \\
\hline & & $\begin{array}{l}\text { Xia-Jiang } \\
\text { variant of } \\
\text { the } \\
\text { Chengbeixi } \\
\text { culture }\end{array}$ & $\begin{array}{l}\text { Chengbeixi } \\
\text { culture }\end{array}$ & $\begin{array}{l}\text { Zaoshi } \\
\text { culture }\end{array}$ & $\begin{array}{l}\text { Gaomiao } \\
\text { variant }\end{array}$ & & & & & & \\
\hline \multirow[t]{2}{*}{$5000-3000 \mathrm{BC}$} & $\begin{array}{l}\text { Early Phase of } \\
\text { Late } \\
\text { Neolithic }\end{array}$ & $\begin{array}{l}\text { Xia-Jiang } \\
\text { variant of } \\
\text { the Daxi } \\
\text { culture }\end{array}$ & Daxi culture & Daxi culture & $\begin{array}{l}\text { Late Gao- } \\
\text { miao }\end{array}$ & $\begin{array}{l}\text { Shinianshan } \\
\text { culture }\end{array}$ & Hemudu culture & $\begin{array}{l}\text { Dingsishan } \\
\text { culture }\end{array}$ & $\begin{array}{c}\text { Xiantouling } \\
\text { culture }^{* *}\end{array}$ & & \\
\hline & & & & & $\begin{array}{l}\text { Yuanshui } \\
\text { variant of } \\
\text { the Daxi } \\
\text { culture* }\end{array}$ & & Majiabang culture & & & $\begin{array}{l}\text { Keqiutou } \\
\text { \& } \\
\text { Fuguo- } \\
\text { dun } \\
\text { culture }\end{array}$ & \\
\hline
\end{tabular}

\section{Research}




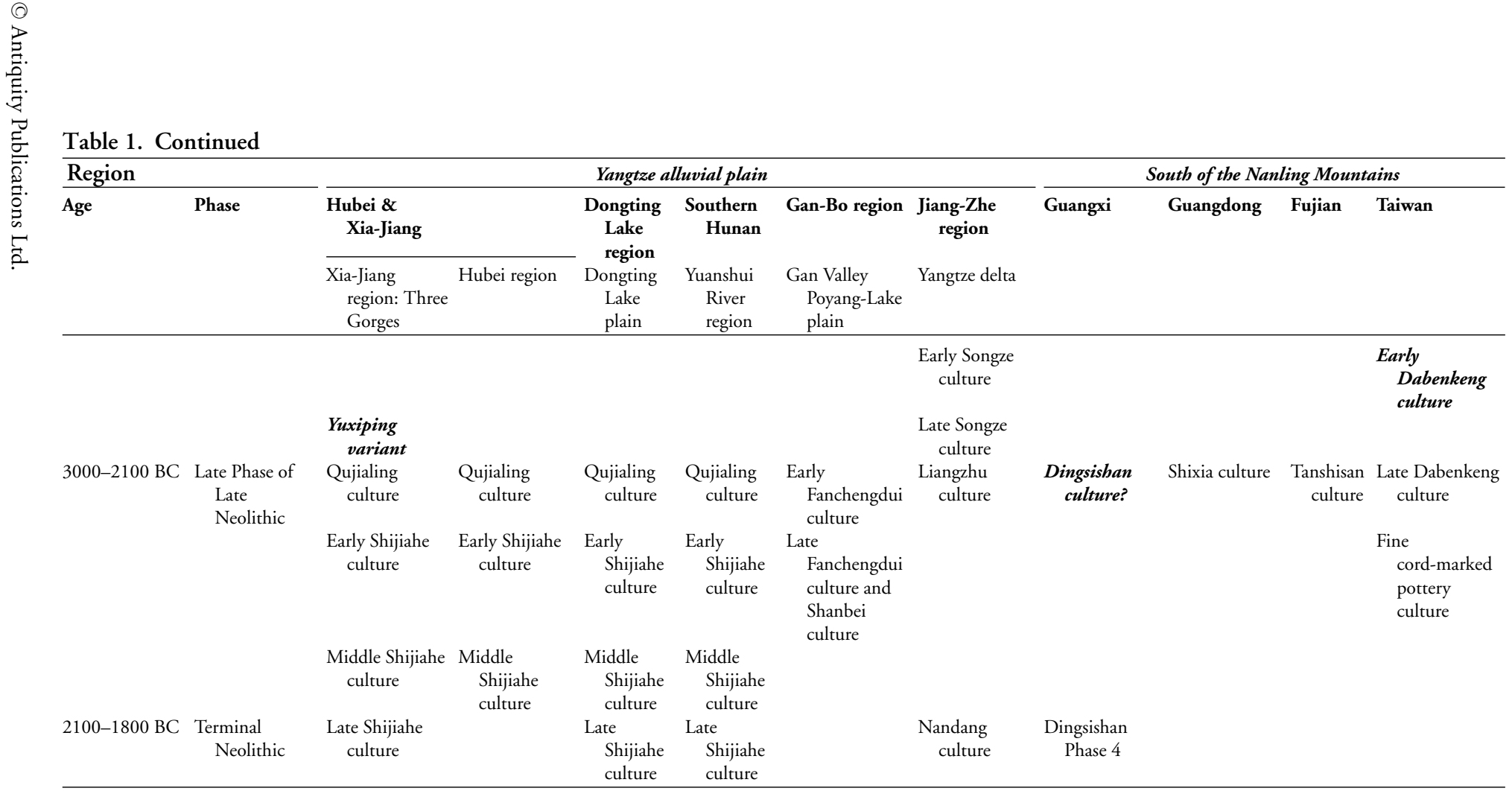

*Alternatively known as the Songxikou culture

${ }^{* *}$ Alternatively known as the Lingnan variant of the Daxi culture 


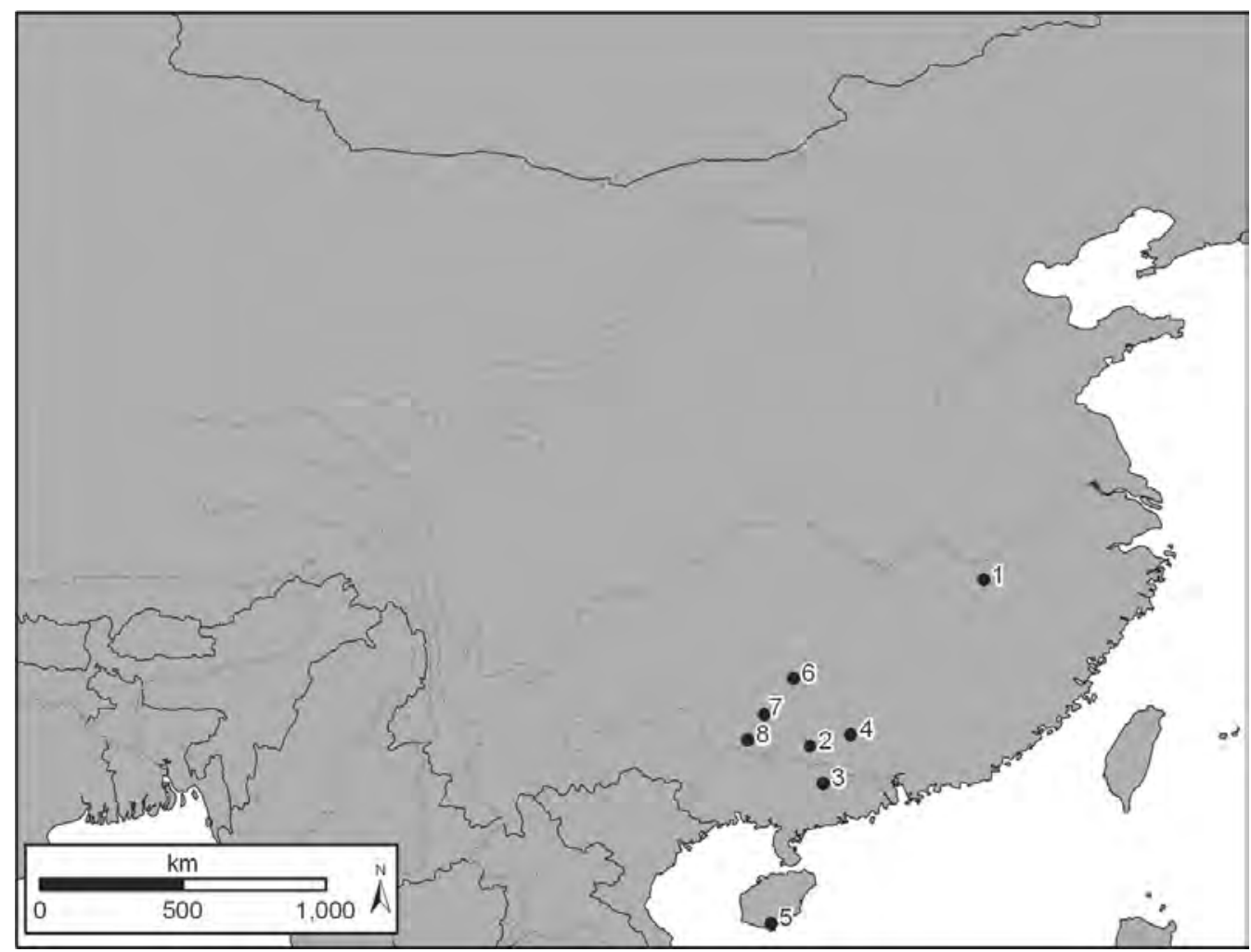

Figure 1. Location of key cave sites dating between 18000 and 7000 BC: 1) Xianrendong and Diaotonghuan, Wannian county, Jiangxi; 2) Huangyandong, Fengkai county, Guangdong; 3) Dushizai, Yangchun county, Guangdong; 4) Niulandong, Yingde county, Guangdong; 5) Luobidong, Sanya county, Hainan; 6) Yuchanyan, Dao county, Hunan; 7) Zengpiyan, Miaoyan and Dayan, Guilin county, Guangxi; 8) Bailiandong and Liyuzui, Liuzhou city, Guangxi.

county (Hunan); Zengpiyan, Miaoyan and Dayan in Guilin, and Bailiandong and Liyuzui in Liuzhou (Guangxi). Similar cave deposits also occur in northern Vietnam. Chinese researchers previously dated these cave middens to the Early Holocene (Yuan 1991; Jiao 1994: 1-24; Wu 1999: 6-18), but new radiocarbon dates suggest they are older. For instance, the beginning of this phase at Xianrendong, Yuchanyan and Miaoyan is dated to $c .18000-$ 15000 cal BC (e.g. Lu, T.L-D. 1999; Zhang, C. 1999; Zhao \& Wu 2003: 98-100; Boaretto et al. 2009). The shell middens in these caves continued until the identifiable beginnings of rice cultivation in the Pengtoushan phase, c. $7000 \mathrm{BC}$, during the Neolithic of the Middle Yangtze.

In terms of stone technology, the assemblages in southern China, especially Lingnan (south of the Nanling Mountains), are similar to those of the Hoabinhian in Southeast Asia (Jiao 1994: 1-24). For instance, stone artefacts in southern China continued to be used to make types of pebble tools and flakes that some Chinese archaeologists have associated with wild plant collection and processing (Wang, Y.P. 2005). From 30000 BP there was a change to a greater use of small flake tools, such as scrapers and points. These trends can be seen in the layer sequence in Bailiandong Cave in Liuzhou, Guangxi (Figure 1, no.

(C) Antiquity Publications Ltd. 


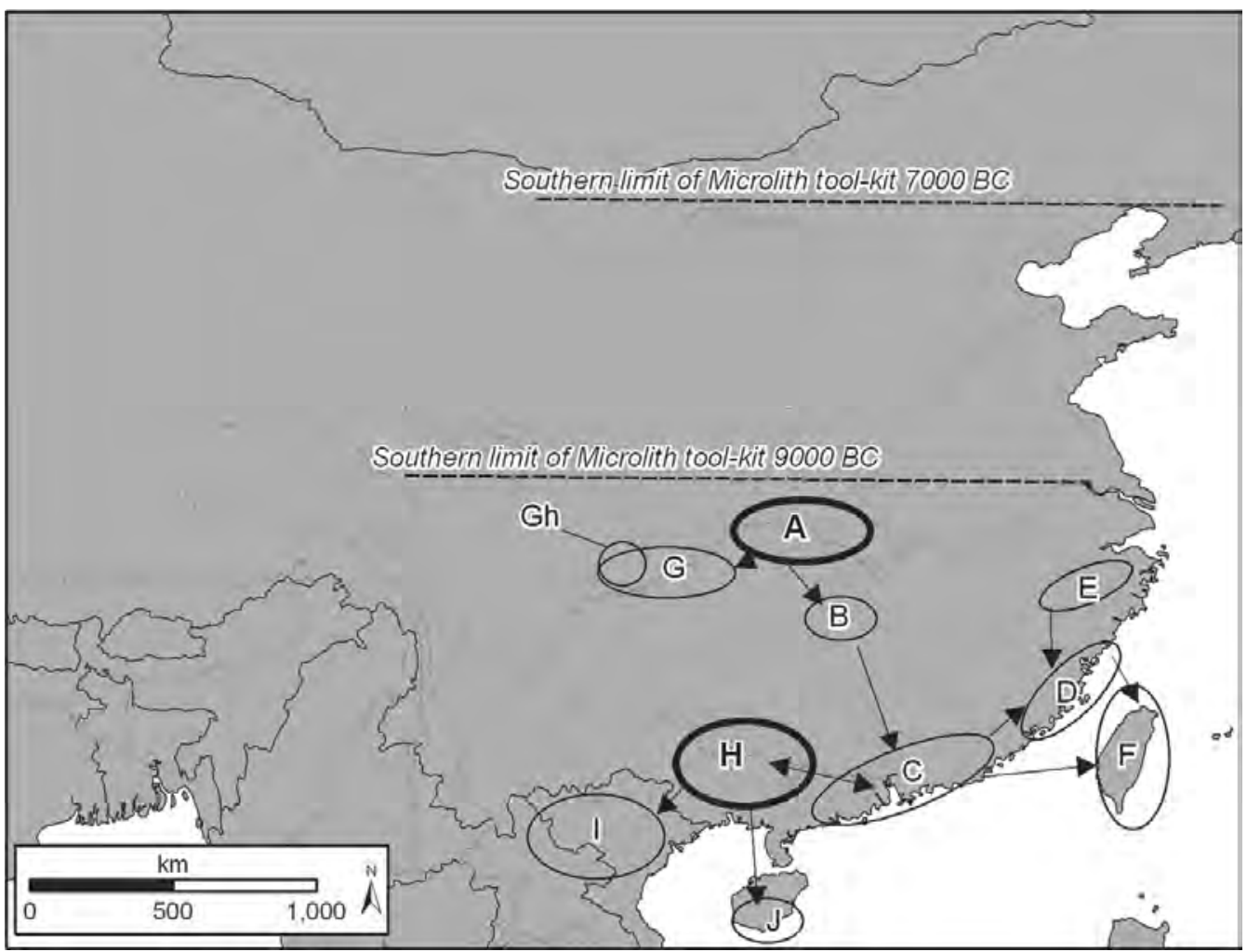

Figure 2. Suggested pre-farming cultural relationships in southern China: A) initial agricultural societies in the Middle Yangtze Valley. It is proposed that $B$ developed on the periphery of $A$, and Gh developed on the periphery of $G$, but was originally from A. Later, group B moved to coastal south-eastern China to become $C$ and D, and finally $F$, possibly with other influences from area $E$ (Lower Yangtze). Area $H$ was occupied by indigenous complex hunter-gatherers, descendants of the makers of pebble and flake tools. A) Pengtoushan-Zaoshi, 7000-5000 BC; B) Gaomiao, 5500-3500 BC; C) Xiantouling, 5000-3500/3000 BC; D) Keqiutou, 4500-3500 BC; E) unknown culture in the mountain regions near the Lower Yangtze River; F) Early Dabenkeng, 4000-3500 BC; G) Chengbeixi-Daxi, 5500-3000 BC; Gh) Xia-Jiang variant of the Chengbeixi-Daxi cultures \& Yuxiping variant, 5500-3000 BC; H) Dingsishan, 7000-3000 BC; I) Da But, 5500-2000 $B C$; J) Hainan Island, 4000-3000 BC.

8). In northern China, contemporary sites contain a microlithic assemblage, regarded as representing a hunting economy (Wang, Y.P. 2005), found mostly in open sites.

The main lithic industry found in Xianrendong, Bailiandong and Liyuzui during this phase included chert and quartz scrapers, pointed tools and other small flake tools. Bone and antler tools included awls, points and possible hoes. Knives with one or two holes were made of large bivalve shells. At Xianrendong, bone needles, arrowheads, fishing spear points, and shell knives were also found. Coarse pottery with temper of quartz grit was found in Xianrendong, Diaotonghuan, Yuchanyan, Dayan, Miaoyan, Zengpiyan and Niulandong caves. The oldest pottery is either plain or combed with a multiple toothed tool to form parallel rib-like striations over the surface. Later pottery is cord-impressed (Zhang, C. 2007: 1-16).

(C) Antiquity Publications Ltd. 


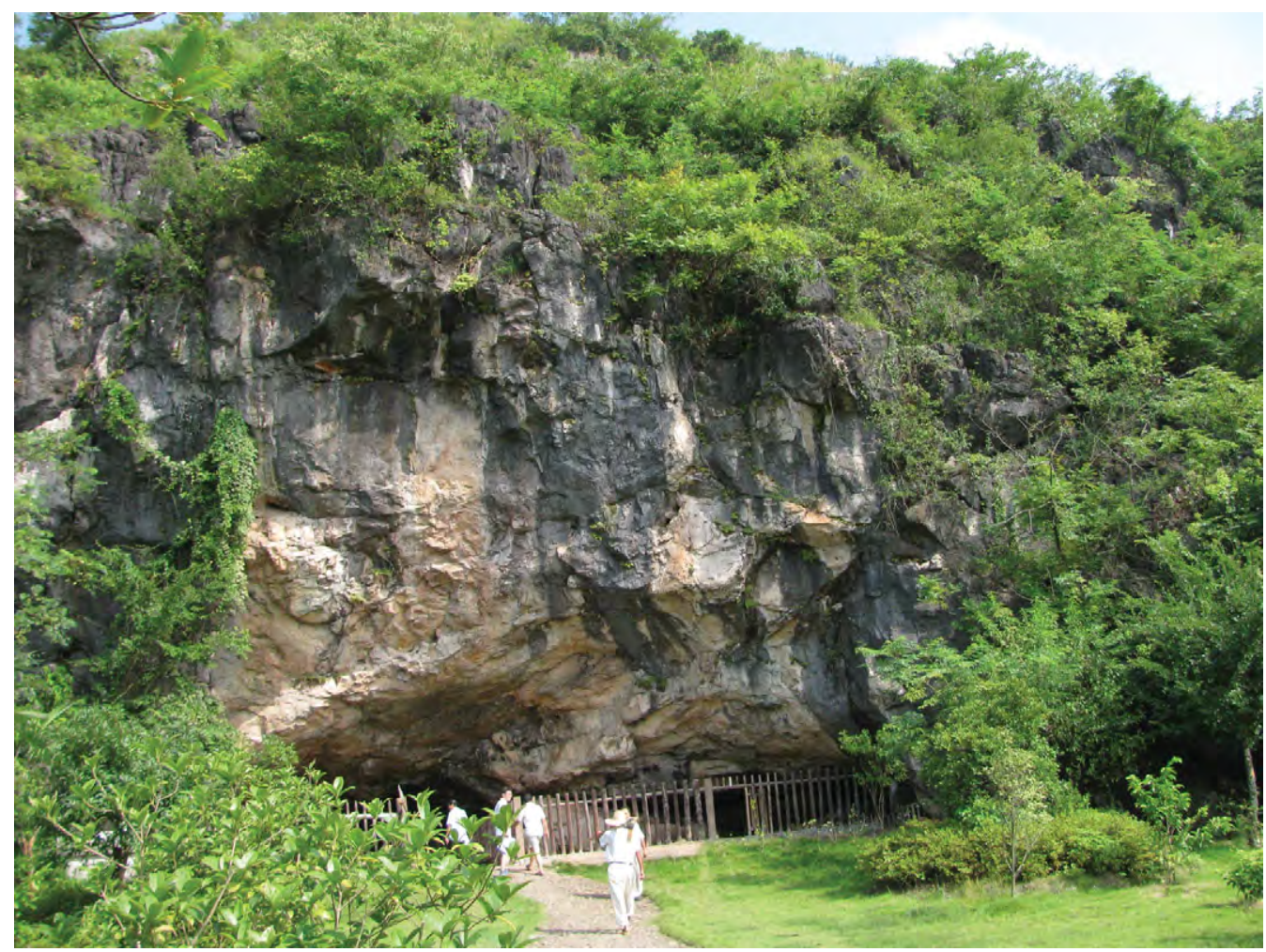

Figure 3. Xianrendong Cave, Jiangxi Province (photograph: Hsiao-chun Hung).

Characteristic of this phase in the excavated caves is an apparent increase through time in the number of animal species exploited. Generally, the caves yield 20-30 types of food animal, especially deer, such as Cervus unicolor, Muntiacus muntjak, Cervus nippon taiouanus, Muntiacus reevesi and Moschus berezovskii. The aquatic animals are mainly shellfish, fish and turtles, and in Xianrendong, Yuchanyan, and Zengpiyan there are bird bones. Plant macroremains recovered from Yuchanyan and Zengpiyan include Chinese gooseberries, wild grapes, plums, Chinese hackberries, hickory nuts and many other edible plant seeds. In Zengpiyan there were also unidentified charred tubers (possibly Dioscorea sp. and Colocasia sp.) (Yuan 2000: 35; IA, CASS et al. 2003: 343). Although a very small number of Oryza sativa phytoliths occur in the Xianrendong, Diaotonghuan, Niulandong and Yuchanyan deposits (Gu 1999: 113-206; Zhang, W.X. 2000: 122), there is insufficient evidence to indicate rice cultivation (Nakamura 2000: 1-11).

The new types of stone artefact, bone tools and pottery in this phase, as well as the apparent diversification of the fishing-hunting-gathering economy, are to some degree similar to the following Neolithic cultures, and many Chinese archaeologists regard this phase as the origin of the Neolithic in southern China. However, due to the absence of farming we prefer to designate it as the Late/Final Palaeolithic phase.

(C) Antiquity Publications Ltd. 


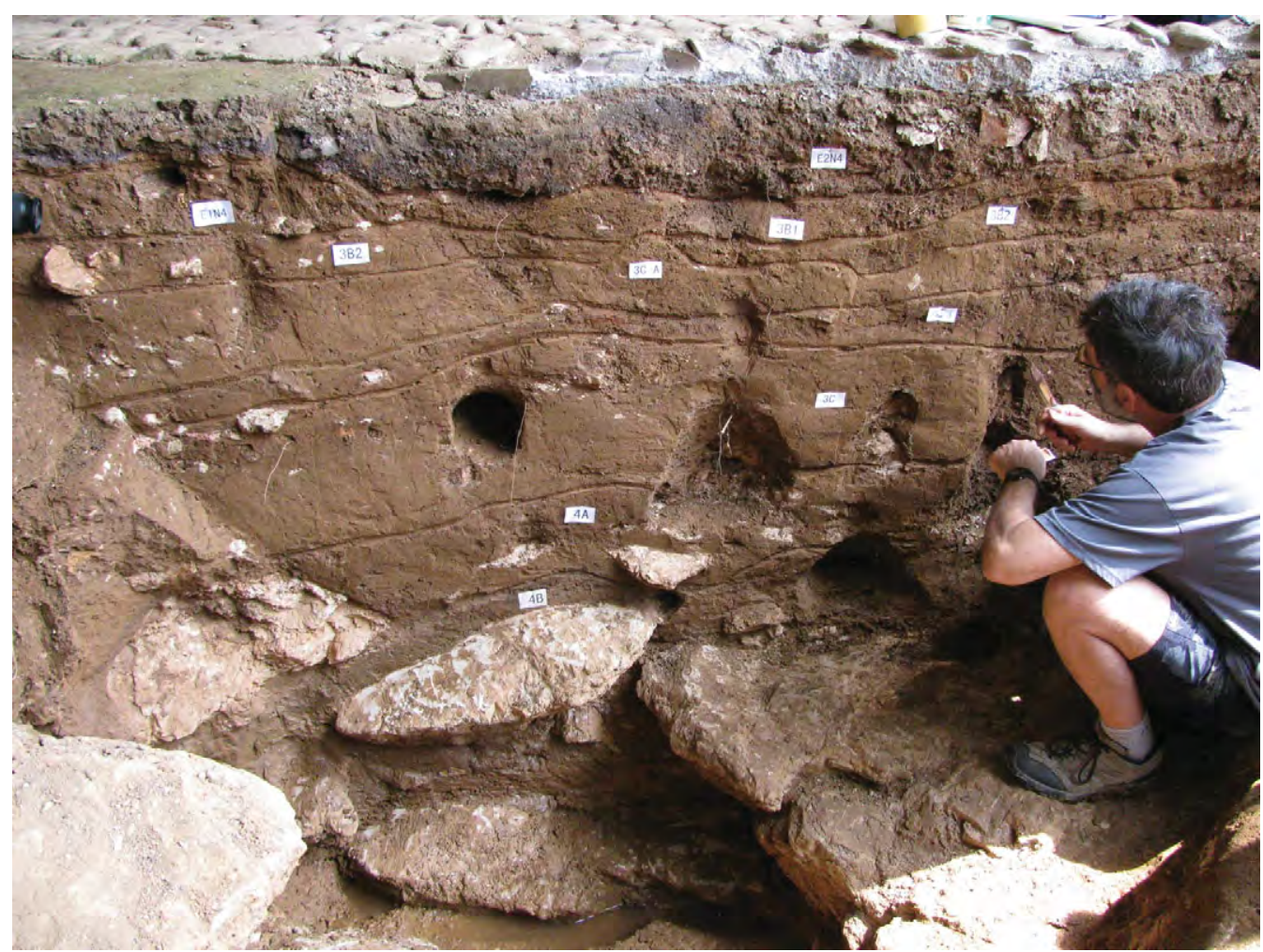

Figure 4. Paul Goldberg examining the profile of Xianrendong Cave in Jiangxi Province. Early pottery from layer 3C(1)A is dated to c. $16000 \mathrm{BC}$ and from $3 C(1) B($ below $A$ ) is dated to c. 18000 BC (photograph: Hsiao-chun Hung).

\section{Shell midden sites in Guangxi and northern Vietnam: Dingsishan \& Da But (7000-3000 BC) (Zones H \& I in Figure 2)}

From $c .7000 \mathrm{BC}$ onwards, open settlements began to appear on river terraces, and represent the origin points of regional farming cultures. However, cave occupation endured, for example until 6000 BC in Xianrendong and 5000-4000 BC in Zengpiyan. Moreover, while rice-growing economies were developing in the Middle and Lower Yangtze, a contemporary complex hunting-gathering group termed the Dingsishan culture continued in existence and grew (Guangxi Team et al. 1998; Fu 2002a).

Dingsishan cultural shell middens are widely distributed in Guangxi, western Guangdong and northern Vietnam $c$. 7000-3000 BC. Most of them are located on the terraces of the Zuojiang, Youjiang and Yongjiang rivers near Nanning, in southern Guangxi. Dingsishan subsistence during phases 1 to $3(7000-3000 / 2100$ BC) is suggested by phytoliths of grasses, palms, cucurbits and annonaceae. There is no evidence for rice phytoliths until Dingsishan phase 4 (Zhao et al. 2005: 76-84), c. 2500-2000 BC (Zhang \& Hung 2010).

The size of the shell midden at Dingsishan is around $5000 \mathrm{~m}^{2}$, and excavation has revealed the existence of separate living areas, a cemetery and areas for dumping refuse. Sixteen burials have been excavated from phase 2 and 133 from phase 3 , within a $500 \mathrm{~m}^{2}$ excavated area (C) Antiquity Publications Ltd. 


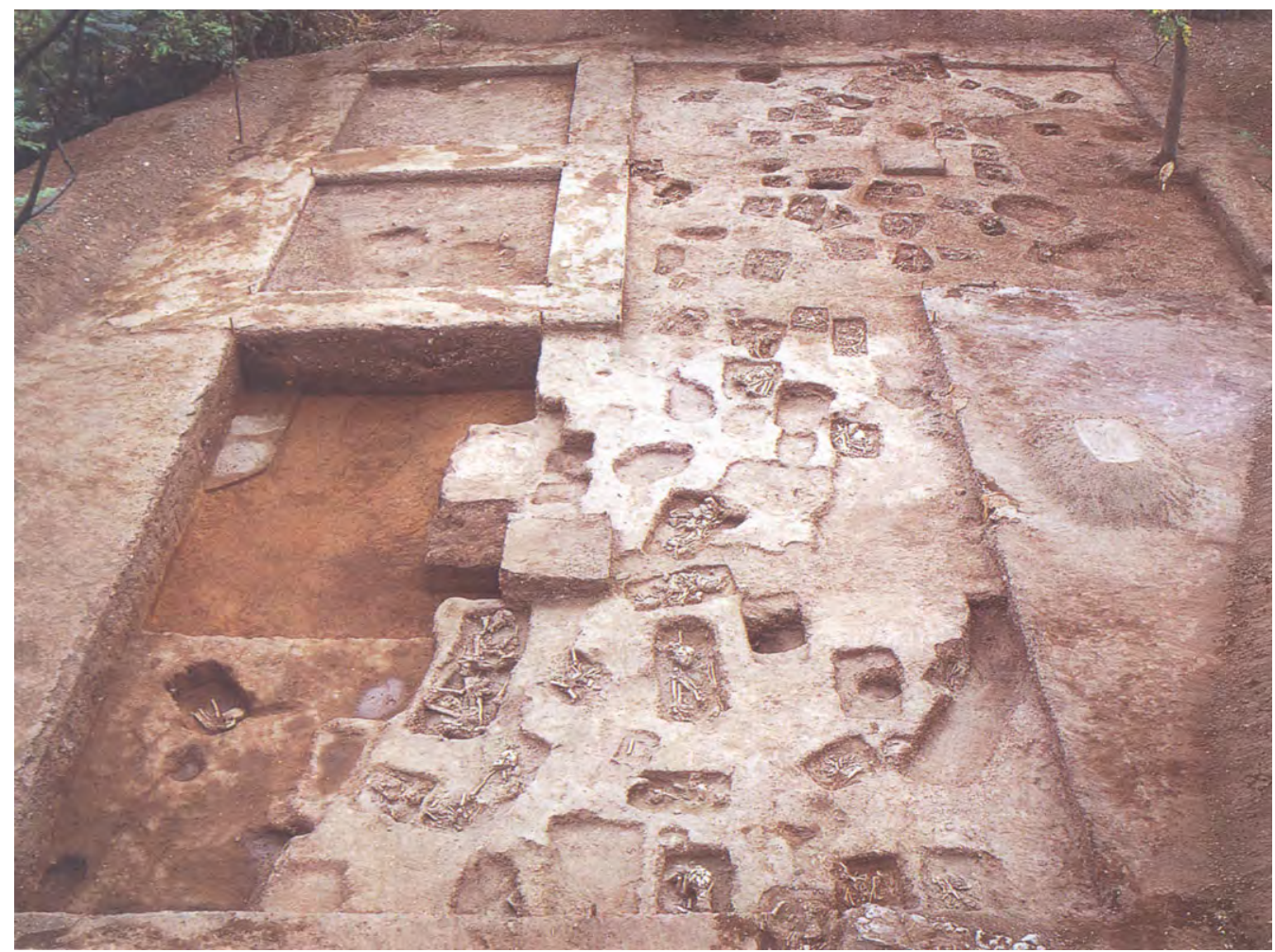

Figure 5. The Dingsishan cemetery site in southern Guangxi (Fu 2002b: 237, photograph courtesy of Fu Xian-guo).

(Figure 5). These cemeteries included flexed, crouched and even dismembered burials, all without grave goods. A pottery manufacturing workshop of this culture has been reported from Baozitou shell midden (Guangxi Team et al. 2003). This evidence for workshops and cemeteries suggests that these shell middens could have been occupied through a long period.

The artefacts found in Dingsishan shell middens (phases 1 to 3 ) include polished stone axes and adzes (made of stone and bone), arrowheads, awls, needles, spears and hooks (all made of bone), shell tools and pottery. The most common shell tools are perforated socalled fish-headed knives. The pottery was greyish-brown in colour with coarse quartz or sand temper. Pottery surfaces are parallel ribbed or cord marked. At both Dingsishan and Baozitou, the pottery assemblage can be divided into two cultural phases: the earlier phase with pottery distinguished with quartz temper and parallel ribbing; and a later phase with pottery featuring sand or crushed shell and cord-marked decoration.

Large quantities of aquatic and terrestrial animal bones have been discovered in Dingsishan sites. A systematic study of the animal remains unearthed from 10 separate shell middens of the Dingsishan cultural phase in the Yongjiang Valley suggests that 84 species belonging to seven classes of animal (Gastropoda, Lamellibranchia, Crustacea, Pisces, Reptilia, Aves, Mammalia) were exploited during this cultural phase (Lu, P. 2010). In Dingsishan itself, there were 74 species (Lu, P. 2010: 75-80) (see Table 2). Bones of domestic dog appeared

(C) Antiquity Publications Ltd. 
Table 2. Animal remains from the Dingsishan shell midden in southern Guangxi (after Lu, P. 2010).

\begin{tabular}{|c|c|c|c|c|c|}
\hline Class & English name & Latin name & Class & English name & Latin name \\
\hline \multirow[t]{21}{*}{ Gastropoda } & \multirow[t]{21}{*}{ River snail } & Cipangopaludina hainanensis (Kobelt) & Crustacea & & Decapoda \\
\hline & & Bellamya quadratus (Benson) & Pisces & Common carp & Cyprinidae \\
\hline & & Bellamya mutica (Kobelt) & & Black carp & $\begin{array}{l}\text { Mylopharyngodon piceus (Richardson } \\
\text { 1846) }\end{array}$ \\
\hline & & Bellamya rivularis (Kobelt) & & Grass carp & $\begin{array}{l}\text { Ctenopharyngodon idella } \\
\text { (Valenciennes 1844) }\end{array}$ \\
\hline & & Bellamya wilhelmi (Yen) & & Yellowcheek carp & $\begin{array}{l}\text { Elopichthys bambusa (Richardson } \\
\text { 1845) }\end{array}$ \\
\hline & & Bellamya polyzonatus (Frauenfeld) & Reptilia & Crocodile/Aligator & Crocodylia \\
\hline & & Bellamya costatus (Quoi \& Gaimard) & & Pond, box and leaf turtles & Emydidae \\
\hline & & Bellamya thersites (Reeve) & & Asian giant soft shelled turtle & Pelochelys cantorii (Gray 1864) \\
\hline & & Bellamya haudei (Dautzenberg \& Fischer) & & Chinese softshell turtle & Pelodiscus sinensis (Wiegmann 1835) \\
\hline & & Bellamya sp. & Aves & Bird & \\
\hline & & Rivularia porcellanea (Kobelt) & Mammalia & Old World monkey & Cercopithecidae \\
\hline & & Rivularia rusiostoma (Gredler) & & Domestic dog & Canis lupus familiaris (Linnaeus 1758) \\
\hline & & Margarya meslanioides (Nevill) & & Raccoon dog & Nyctereutes procyonoides (Gray 1834) \\
\hline & & Margarya mansuyi (Dautzenberg \& Fischer) & & Asian black bear & $\begin{array}{l}\text { Selenarctos thibetanus (G.. Cuvier } \\
\text { 1823) }\end{array}$ \\
\hline & & Semisucospira henriettae (Gray) & & Hog Badger & Arctonyx collaris (F. Cuvier 1825) \\
\hline & & Sulcospira hainanensis (Brot) & & Eurasian otter & Lutra lutra (Linnaeus) 1758 \\
\hline & & Cyclophorus songmaensis (Morelet) & & Masked Palm Civet & $\begin{array}{l}\text { Paguma larvata (Hamilton-Smith } \\
\text { 1831) }\end{array}$ \\
\hline & & Eusphaedusa ridicula (Gredler) & & Asian Elephant & Elephas maximus (Linnaeus 1758) \\
\hline & & Opeas gracilior (Credaler) & & Rhinosceros & Rhinoceros sp. \\
\hline & & Camaena hainanensis (H. Adams) & & Pig & Sus sp (p). \\
\hline & & Bradybaena similaris similaris (Ferussac) & & Northern Red Muntjac & Muntiacus vaginalis (Boddaert 1785) \\
\hline \multirow[t]{9}{*}{ Lamellibranchia } & Mussel & Limnoperna sp. & & Chinese Muntjac & Muntiacus reevesi (Ogilby 1839) \\
\hline & Freshwater pearl mussel & Margaritiana sp. & & Sambar deer & Rusa unicolor (Kerr 1792) \\
\hline & \multirow[t]{7}{*}{ Clam } & Acuticosta sp. & & Sika deer & Cervus Nippon (Temminck 1838) \\
\hline & & Lanceolaria triformis (Heude) & & Buffalo & Bubalus sp. \\
\hline & & Lamprotula leai (Gray) & & Field vole & Microtus sp. \\
\hline & & Lamprotula scripta (Heude) & & Eurasian beaver & Castor fiber (Linnaeus 1758) \\
\hline & & Lamprotula polysticta (Heude) & & Bamboo rat & Rhizomys sp. \\
\hline & & Lamprotula mansuyi (Dautzenberg \& Fischer) & & Himalayan porcupine & $\begin{array}{l}\text { Hystrix (brachyura) hodgsoni (Gray } \\
\text { 1847) }\end{array}$ \\
\hline & & $\begin{array}{l}\text { Lamprotula sp. } \\
\text { Anodonta sp. } \\
\text { Corbicula fluminea (Müller) }\end{array}$ & & Hare & Lepus sp. \\
\hline
\end{tabular}


at about $5000 \mathrm{BC}$, but without domestic pig or domestic water buffalo in association (Lu, P. 2010).

Perhaps due to an increasing population, these Dingsishan foragers gradually expanded into neighbouring river systems. According to current records, sites of this type first appeared in the Zuojiang and Yongjiang valleys of southern Guangxi at $c .7000 \mathrm{BC}$, and then expanded into the Youjiang, Hongshui, Yujiang, Xunjiang, Qianjiang, and Xijiang valleys in western Guangdong by c. 4000-3500 BC. At about the same time they spread into, or co-developed within, northern Vietnam, where they formed the Da But or Bacsonian culture of the late Hoabinhian (Nguyen, V. 2005).

The Da But cultural sites include Da But, Con Co Ngua, Ban Ban Thuy, Lang Cong and Go Trung in Thanh Hoa Province of northern Vietnam, and might also have occurred northwards in Hoa Binh, Ha Nam and Ha Tay provinces. At Con Co Ngua, more than 100 skeletons (two human teeth dated to $c .3000 \pm 30$ BC, P. Bellwood \& D. Huffer pers. comms) were found buried in sitting positions in cylindrical pits in an area of about $200 \mathrm{~m}^{2}$. Vietnamese archaeologists believe that the Da But populations subsisted mainly by collecting plants and hunting. They were relatively sedentary (Nguyen, V. 2005). The pottery, stone artefacts and burial practices (especially the seated and crouched burials) in Da But sites are identical to those from Dingsishan and Zengpiyan. According to the available radiocarbon dates from the Da But sites (Nguyen, V. 2005; Nguyen, W.H. 2006), the duration of the Da But culture was $c$. 5500-2000 BC, but Nguyen Viet suggested that Da But itself could have been occupied before 6000 BC. We propose that the Da But and Dingsishan cultures shared a cultural origin.

Agriculture began to appear in the Yangtze Valley after c. $7000 \mathrm{BC}$ and domestic pigs and textiles c. $5500 \mathrm{BC}$; but all were absent in Dingsishan (phases 1 to 3) and Da But. In terms of residential locations, subsistence strategies, burial practices, and various aspects of material culture, these Dingsishan-related midden sites reveal little significant change through time, although artefact forms and styles show slight variation from site to site.

\section{Shell midden sites in the Middle Yuanshui River, and fish bone middens in the Xia-Jiang region: Gaomiao \& Chengbeixi-Daxi-Yuxiping (5500-3000 BC) (Figure 2, zones B and Gh)}

Another group of complex hunter-gatherers appeared around $5500 \mathrm{BC}$ in the Middle Yuanshui River and the Xia-Jiang region, located between the Middle Yangtze and southwest China (Figure 2). In terms of chronology, the Gaomiao group (Zone B) of the Middle Yuanshui River appeared earlier, contemporary with the early Zaoshi (Zone A) and the Chengbeixi (Zone G) farming cultures in the Middle Yangtze Valley, with which they shared material cultural relationships. Related hunter-gatherer groups appeared in the Xia-Jiang region a little later (Zone Gh), during the late phase of the Chengbeixi culture. Interestingly, the Gaomiao sites are all shell middens, and the Xia-Jiang sites (Zone Gh) are all concentrated piles of fish bones. Neither has evidence for agriculture. Typical 
Chengbeixi-Daxi cultural sites in the Middle Yangtze contain plentiful remains of cultivated rice, but such remains are absent in the Xia-Jiang region.

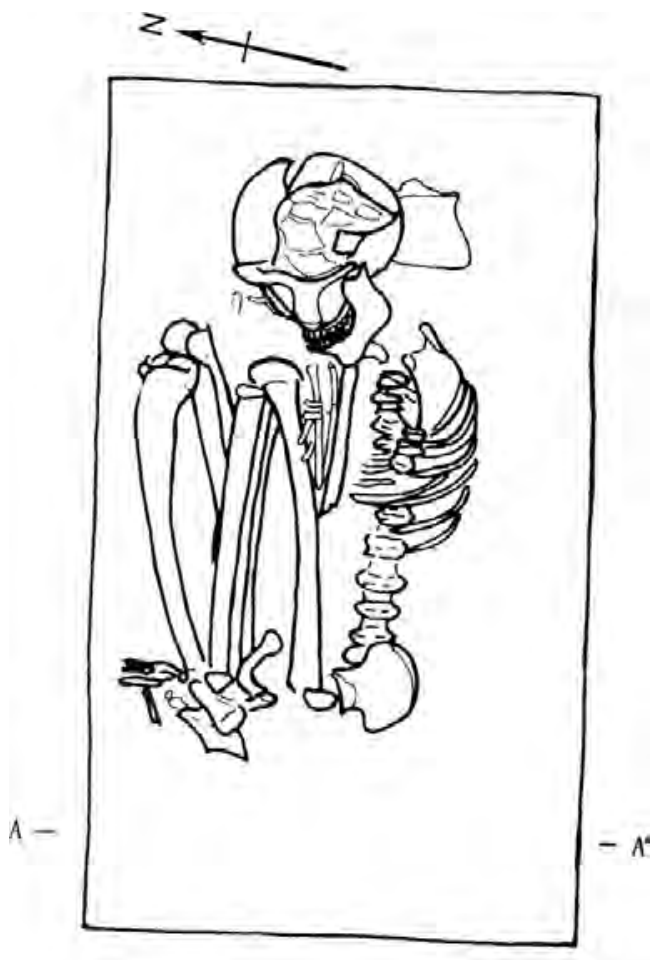

A

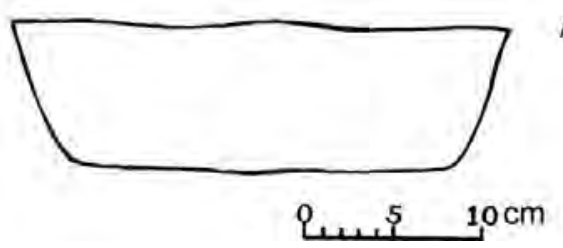

Figure 6. A flexed burial excavated from Gaomiao, Hunan Province (IA, Hunan 2000: 6)
At Gaomiao (IA, Hunan 2000; He, G. 2006a), a sacrificial site featuring postholes and offering pits was discovered. Burnt bones of cattle, deer, turtle and fish, and a large quantity of gastropod shells, were found in the pits. Nearby, a three-roomed house of about $40 \mathrm{~m}^{2}$ was excavated. So far, more than 20 such houses from early and late phases of occupation have been excavated at Gaomiao, constructed at ground level and enclosing $18-40 \mathrm{~m}^{2}$, each with two or three rooms. More than 30 burials have been reported, the earlier ones flexed on their sides without grave goods (Figure 6). However, the later phase contained extended burials with jade and pottery grave goods, likely influenced by the agricultural Daxi culture in the Dongting Lake area.

Many pebble tools, polished axes, adzes, chisels, millstones, pestles and net sinkers were found in the Gaomiao sites. In the later phase shouldered axes and adzes, and yue (large polished axes) appeared. Bone and antler implements include awls, needles, knives, daggers and perforated shell knives, but never in large quantities. The early Gaomiao pottery forms include $f u$, jars, plates and bowls, with very fine decoration including cord impression and dentate stamping, the latter forming animal faces, phoenixes, waves, trapezoids, circles and band-like motifs (Figure $7 \& 8$ ).

All Gaomiao sites are shell middens that contain freshwater gastropods and bivalves, fish, turtles and other aquatic animals. There are also a large number of terrestrial mammals including deer, pigs, bear, elephant, rhinoceros and tapir. Some of the pigs have been identified as domestic, but there are no rice phytoliths (He, G. 2006b). Currently, only two sherds contained rice husks (from Zhenxikou), and there are three sherds with rice grain impressions and one with rice husk impressions from Gaomiao itself ( $\mathrm{Gu} \&$ Zhao 2009). However, the sources of these sherds are unknown. It is necessary to emphasise that contemporary sites in Hunan have unearthed abundant remains of cultivated rice, but this is almost absent in Gaomiao.

(C) Antiquity Publications Ltd. 

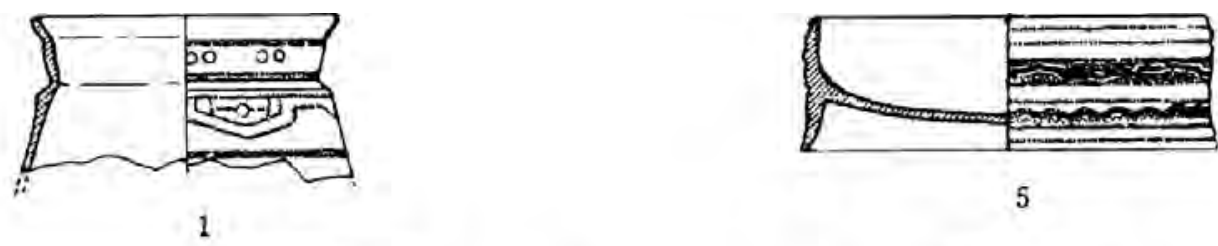

5
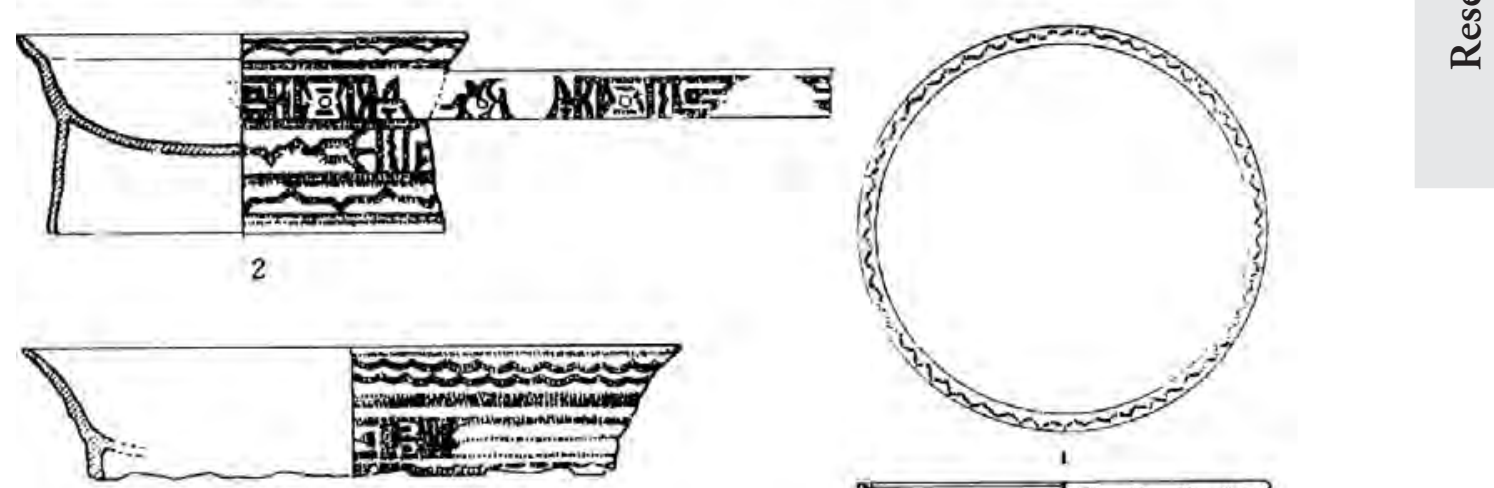

3
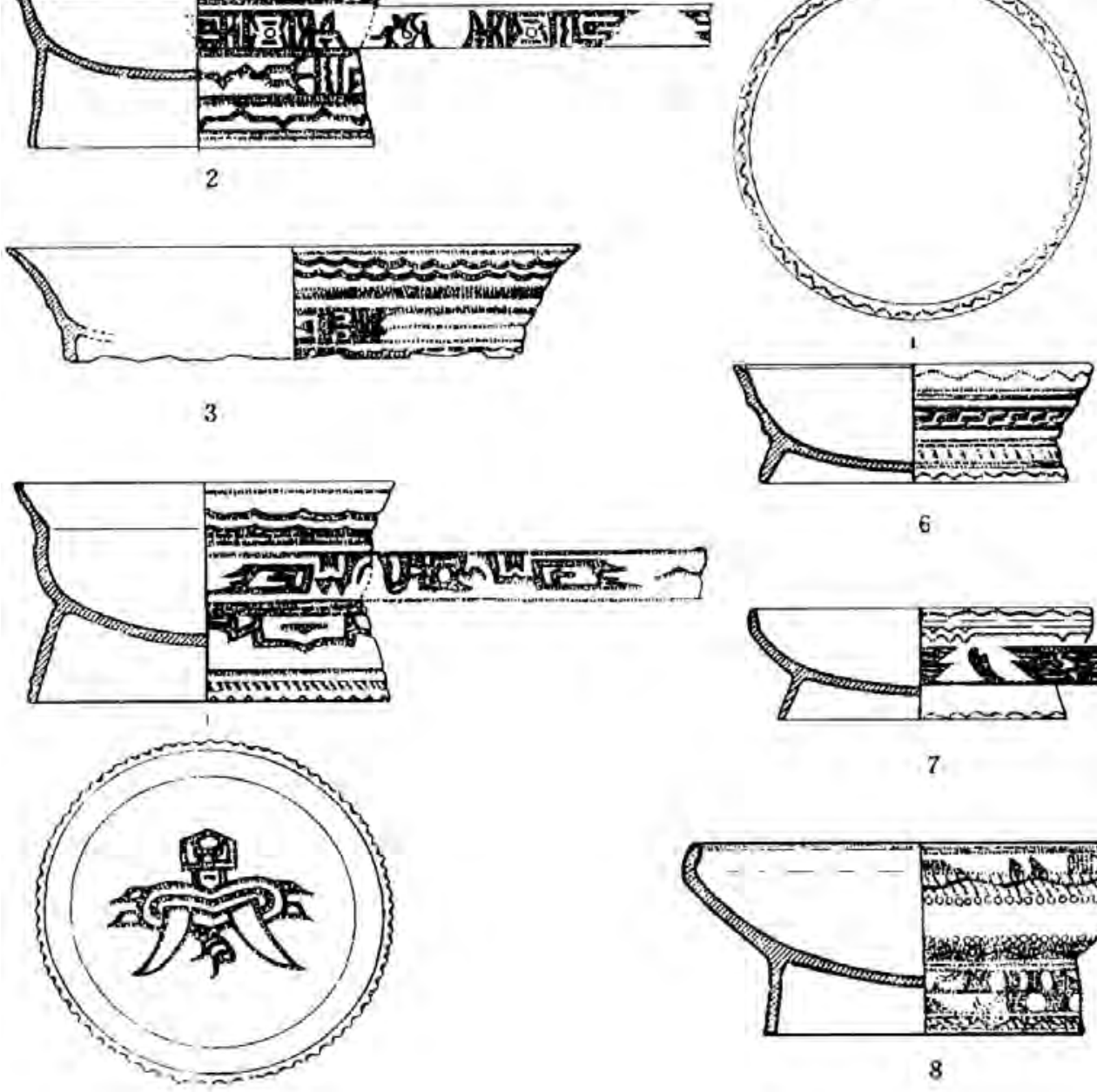

6

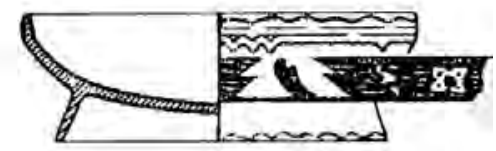

7

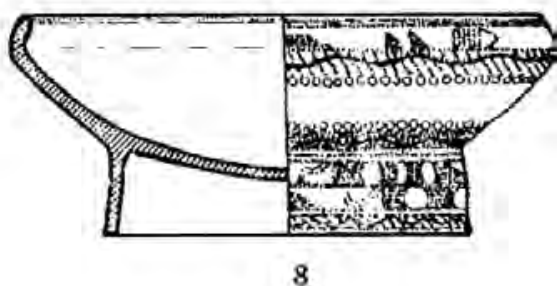

4

Figure 7. Decorated pottery vessels from Gaomiao, Hunan Province, similar to incised pottery from Xiantouling in Guangdong Province, c. 5000 BC. Scale = 1:4 (IA, Hunan 2000: 11).

At the same time, large quantities of fish bones, without shells, have been discovered in Xia-Jiang (Zone Gh). Most are located where fish of the species Mylopharyngodon piceus, Ctenopharyn odon idellus, Hypophthalmichthys molitrix and Aristichthys nobilis spawn in the Yangtze River (Ma 1988).

C) Antiquity Publications Ltd. 


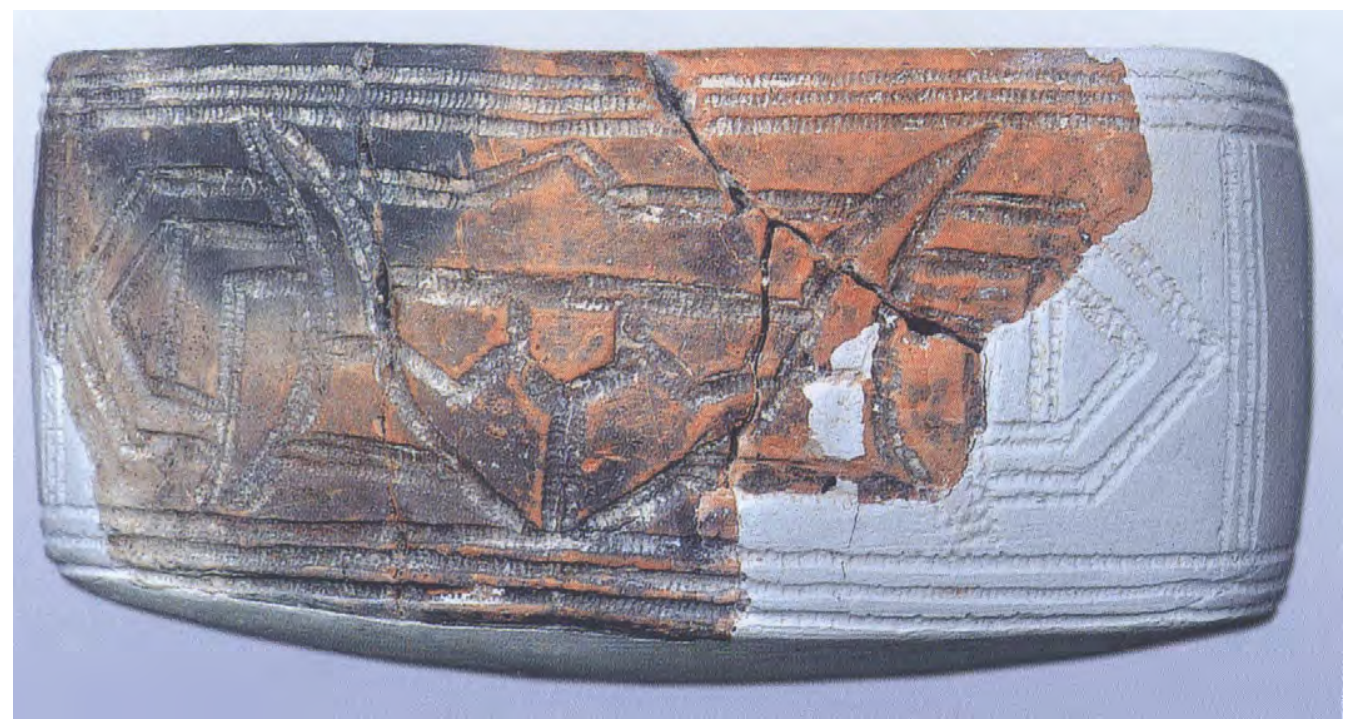

Figure 8. Decorated pottery vessel from Gaomiao, Hunan Province, c. 5000 BC (IA, Hunan 2006: pl. 4).

It is possible to explain these sites by assuming that Chengbeixi immigrants gave up rice farming after entering Xia-Jiang, where there is a lack of cultivable land in the valley bottom. Likewise, the Gaomiao culture (Zone B) could have developed from the agricultural Pengtoushan culture (Zone A). Such origins from agricultural populations could also explain the rarity of domestic pig bones in these derivative hunting and gathering contexts. Both Gaomiao and the Xia-Jiang variant of the Chengbeixi-Daxi culture had well-developed pottery and stone adze/axe industries, especially in the Three Gorges region in Xia-Jiang. Spindle whorls have also been found in these sites. In the late Gaomiao and the Xia-Jiang variant of the Daxi culture, foraging cultures that developed in the Middle Yuanshui River and in Xia-Jiang expanded into northern Guizhou (Wang, H.G. 2006: 3-10).

\section{Sand dune sites and early shell middens in coastal south-eastern China (5000-3500/3000 BC) (Zones C, D \& F in Figure 2)}

Between 5000 and 3500 BC, pottery-using foragers made an appearance in Guangdong, Guangxi and Fujian provinces in coastal south-eastern China, and in coastal northern Vietnam. The earliest recognised group belonged to the Xiantouling or Dawan culture (sometimes termed the Lingnan variant of the Daxi culture) in the Zhujiang (Pearl) delta region and offshore coastal islands (Zone $\mathrm{C}$ ). Most Xiantouling sites are located on sand dunes, but there are shell middens in coastal Guangdong, Fujian and Taiwan.

In the Zhujiang delta, and indeed across the whole of Guangdong, there were no previous pottery-using groups with Neolithic material culture. This suggests that the Xiantouling culture did not have an indigenous source. Most Chinese archaeologists agree that the white and painted pottery styles of this culture in the Zhujiang estuary are derived from Gaomiao, Tangjiagang and Daxi sources in Hunan (e.g. He, J.J. 1994: 71-8; Tang 1999: 83-9).

(C) Antiquity Publications Ltd. 
Others suggest that the incised pottery could be of local derivation (Bu 1999: 48-56), but all agree that continuous influences from Hunan were entering the Zhujiang region during this phase (Pei 1999: 117-31). Amongst evidence for the latter one can include spindle whorls, but bark cloth beaters appear to be local inventions. It is possible that Xiantouling was a mixed-origin assemblage.

More than 10 shell middens have been discovered in Fangcheng and Qinzhou in Guangxi, and Chaoan in Guangdong (Zone C). Yapushan, Malanzuishan, Beixiaoshan and Shiweishan in Chaoan are all estuarine shell middens, facing the ocean. The Keqiutou-Fuguodun shell middens in coastal Fujian and nearby islands (Zone D) and the early Dabenkeng phase sites in Taiwan (Zone F) are the oldest open-air settlements with pottery production and polished stone tools in their regions. Keqiutou is dated to between 4500 and $3500 \mathrm{BC}$ (Lin 2005: 80), equivalent to a late phase of the Xiantouling culture in Guangdong.

As well as estuarine shells, the Sham Wan (Shenwan) site in Hong Kong contained bones of fish, deer and wild pig. Seeds of Ricinus communis (castor-oil plant) and possibly amaranth were found in layer F (Meacham 1978: 270). These discoveries suggest a subsistence strategy reliant on gathering, hunting and fishing. Such a supposition is supported by stable isotope analyses of the human remains (Lu, T.L-D. 2007: 40). The only known domestic animal in coastal southern China during this stage, c. $5000-3000 \mathrm{BC}$, is the domestic dog (Lu, T.L-D. 2007: 40), which is consistent with other zooarchaeological records from Guangxi. It is likely that dogs were domesticated by hunter-gatherers at a very early stage but it was only much later that domestic pigs were introduced into southern China by farmers from the Middle and Lower Yangtze.

The Keqiutou-Fuguodun culture in coastal Fujian and the early Dabenkeng culture in Taiwan have later radiocarbon dates than the Xiantouling culture (Shenzhen Institute 2006; Hung 2008). These people maintained close relations with Xiantouling in Guangdong, and perhaps also received cultural influences from the Lower Yangtze River (Zone E) (Liu \& Guo 2005: 135-95) and other regions. Compared to other non-farming cultures in southern China, these foragers of Middle Holocene coastal south-east China were the most recent and also perhaps, in socio-cultural terms, the most complex.

\section{Discussion: the expansion and decline of complex hunter-gatherers in southern China}

Parallel to the development of agriculture on the Yangtze, from 7000 BC, we have noted the continuous use of caves and defined three main groups of hunter-gatherer-foragers. Of these, the Dingsishan culture in Guangxi developed from the local Palaeolithic and there was no sharp or dramatic cultural change during their long period of development. The Dingsishan people in this regard can be termed indigenous foragers. By contrast, the Gaomiao of the Middle Yuanshui River and the Xia-Jiang variant of the Chengbeixi-Daxi culture and Yuxiping can be termed foragers of Neolithic derivation. The later Xiantouling fisher-forager populations of coastal Guangdong maintained long-term cultural interactions with Gaomiao and Daxi, in the region of the Middle Yangtze, with the Dingsishan in southern Guangxi, and perhaps even with Zengpiyan phase 5 in northern Guangxi. Perhaps in need of food resources, these inland foragers gradually expanded toward the south-eastern 
coastal areas, then across the sea to Hainan (Zone J), Taiwan (Zone F) and other coastal islands.

When the complex hunter-gatherer cultures of the Yuanshui River and the Xia-Jiang regions reached their most developed phases, in c. 5500-3500 BC, agriculture was also progressing rapidly in the Middle and Lower Yangtze Valley. However, the complex forager cultures all began to decline between 3500 and 3000 BC. During the climatic cooling that followed the Early/Mid Holocene optimum, the average annual temperature in southern China was about 2 degrees lower than at present. These changes perhaps affected foraging cultures adversely in south China. At the same time, farming groups from the Middle and Lower Yangtze Valley began to migrate directly into Lingnan and neighbouring areas.

The Yuanshui and Xia-Jiang hunter-gatherers were replaced by the expansive Qujialing farming culture (3000 BC), located along the Middle Yangtze River. Also, during this phase, the numbers of Xiantouling sand dune sites and Keqiutou-Fuguodun shell middens were greatly reduced (Nishitani 1997: 1-56). Agricultural settlements first appeared at Shixia in northern Guangdong, Tanshishan in Fujian, and at Nanguanli (late Dabenkeng phase) in Taiwan. The late-appearing Dingsishan phase 4 cultural assemblage in Guangxi is believed to be associated with rice agriculture.

\section{Conclusion}

As in northern China (Bettinger et al. 2010), the archaeological record in southern China records transitions from non-intensive to intensive hunting and gathering, and further from intensive hunting and gathering to low-level food production, and finally intensive agriculture. Southern China contains the oldest evidence for pottery manufacture and rice cultivation in the world, and we have shown that mixed economies involving intensive hunting and gathering, low-level food production and intensive agriculture, co-existed for 5000 years.

We conclude that, outside agriculture, the Holocene developments south of the Yangtze can be classified into three phases: the first, between 18000 and $7000 \mathrm{BC}$, saw the first pottery production and the continuing use of small cave sites. The second, between 7000 and $5000 \mathrm{BC}$, witnessed the indigenous appearance of the Dingsishan group on river terraces in southern Guangxi. Later, the Gaomiao and Xia-Jiang groups appeared in the Middle Yuanshui and Xia-Jiang regions respectively. It is hypothesised that these groups likely developed from nearby agricultural societies, such as Pengtoushan and Chengbeixi in the Middle Yangtze Valley (for similar examples see Bellwood 2005: 37-9). These groups always maintained close cultural relationships with contemporary agricultural societies. The third phase was one of prosperous development between 5000 and $3000 \mathrm{BC}$, associated with the late Dingsishan, and the Gaomiao and Xia-Jiang variant of the Daxi culture. At the same time, the farming cultures of the Middle and Lower Yangtze also reached high levels of development. Complex hunter-gatherer groups from Guangxi and Hunan migrated into southeastern coastal areas, and settled the Xiantouling sand dune sites in Guangdong, together with coastal shell middens in Guangxi, Guangdong, Fujian, northern Vietnam and Taiwan.

When farmers left the Middle and Lower Yangtze Valley around $3000 \mathrm{BC}$ to enter southern China, they expanded onwards towards mainland and Island Southeast Asia via (C) Antiquity Publications Ltd. 
two routes that involved the dispersal of early Austroasiatic and Austronesian speaking populations (Zhang \& Hung 2010). These expanding farmers thus met indigenous foragers in Guangxi and others of exotic origin in coastal south-east China. As a result, the foraging groups of south China and Southeast Asia became integrated into the developing farming cultures. Such archaeological evidence is consistent with the hypothesis based on human remains from northern Vietnam, namely, that there were two major layers of human settlement in Southeast Asia during the Holocene (Matsumura et al. 2008, 2011).

Although some of the cultural characteristics of the complex hunter-gatherer societies in southern China were similar, there were many aspects of material culture and subsistence that were different. Compared to presumed Palaeolithic subsistence, these late hunter-gatherers in south China developed larger-scale villages with more complex cultural attributes, and we have noted long-term cultural interaction between the latter exotic hunter-gatherer societies and farmers. Bellwood argues that:

Hunter-gatherers would have been unlikely to adopt agriculture if they were not in direct and continuous contact with agriculturalists. They also would not have adopted agriculture by remote action across biogeographical transition zones or uninhabited terrain (Bellwood 2009: 623).

In this article, we have observed different transitions to eventual farming between the indigenous and exotic hunter-gatherer societies of southern China, but many questions still remain to be answered.

\title{
Acknowledgements
}

We are grateful to Professor Peter Bellwood of The Australian National University, Canberra and Dr Mike Carson of University of Guam for giving us invaluable comments on this manuscript. We would like to thank Dr Philip Piper for his help with the terminology of Latin and English names of animal remains. We also wish to thank Professor Martin Carver and two anonymous reviewers for their support and encouragement on this manuscript. This study was funded in part by the Australian Research Council, Canberra and Chiang Ching-Kuo Foundation, Taipei.

\author{
Abbreviations \\ IA: Institute of Archaeology \\ ATGZ: Archaeological Team of the Guangxi Zhuang Autonomous Region \\ CASS: Chinese Academy of Social Science \\ Kaogu: Kaogu (Archaeology) \\ Wenwu: Wenwu (Culture Relic) \\ Dongfang Kaogu (Eastern Archaeology) \\ Dongnan Kaogu Yanjiu (Studies of Southeast Archaeology)
}

\section{References}

BELLWOOD, P. 2005. First farmers. Oxford: Blackwell.

- 2009. The dispersals of established food-producing populations. Current Anthropology 50(5): 621-6.
Bettinger, R.L., L. Barton, C. Morgan, F. Chen, H. WANG, T.P. Guilderson, D. Ji \& D. Zhang. 2010. The transition to agriculture at Dadiwan, People's Republic of China. Current Anthropology 51(5): 703-714. 
Boaretto, E, X.H. Wu, J.R. Yuan, O. Bar-Yosef, V. Chu, Y. Pan, K. LiU, D. Cohen, T.L. JiaO, S.C. Li, H.B. Gu, P. Goldberg \& S. Weiner. 2009. Radiocarbon dating of charcoal and bone collagen associated with early pottery at Yuchanyan Cave, Hunan Province, China. Proceedings of the National Academy of Science 106(24): 9595-9600.

BU, G. 1999. Chronologies and genealogies of the Late Neolithic at the mouth of the Zhujiang River. Wenwu 11: 48-56 (in Chinese).

Crawford, G.W. \& S. Chen. 1998. The origins of rice agriculture: recent progress in East Asia. Antiquity 73: 858-66.

FU, X.G. 2002a. The Dingsishan site and the prehistory of Guangxi, southern China. Bulletin of the Indo-Pacific Prehistory Association 22: 63-72.

- 2002b. The first archaeological culture in GuangxiYongning Dingsishan site, in Wen-ru Li (ed.) Top 100 new archaeological discoveries of China 19901999: 237. Beijing: Wenwu Press (in Chinese).

Fuller, D.Q., L. Qin, Y. Zheng, Z. ZhaO, X. Chen, L.A. Hosoya \& G.P. Sun. 2009. The domestication process and domestication rate in rice: spikelet bases from the Lower Yangtze. Science 323: 1607-1610.

GU, H.B. 1999. Studies of the phytoliths and pollen of the Yingde Niulandong Cave in Guangdong, in Yingde City Museum, Anthropology Department of Zhongshan University \& Guangdong Provincial Museum (ed.) Treatises of international conference on Mesolithic culture: 113-206. Guangzhou: Guangdong People (in Chinese).

Gu, H.B. \& Z.J. ZHAO. 2009. Study on carbonized rice from different cultural phases in Hunan. Dongfang Kaogu 6: 358-65 (in Chinese).

Guangxi Team, IA of CASS, ATGZ \& Nanning Museum. 1998. Excavation at Dingsishan in Yongning, Guangxi. Kaogu 11: 11-33 (in Chinese).

Guangxi Team, IA of CASS \& ATGZ. 2003. Excavation at Baozitou in Nanning, Guangxi. Kaogu 10: 22-34 (in Chinese).

HE, G. 2006a. Reappearance of prehistoric religious and ritual scenario - the Neolithic Gaomiao site in Hongjiang, Hunan. Paper presented at The archaeology forum of the Chinese Academy of Social Sciences: new discoveries in Chinese archaeology in 2005, Chinese Academy of Social Science, Beijing, 10 January 2006 (in Chinese).

- 2006b. The big discovery of Hongjiang Gaomiao site in Hunan. China Cultural Relics News, 6 January 2006, p. 1 (in Chinese).

HE, J.J. 1994. Prehistoric painted pottery and Daxi culture of the Zhujiang River mouth, in C. Tang (ed.) Ancient cultures of south China and neighbouring regions: 71-8. Hong Kong: Chinese University of Hong Kong (in Chinese).
HuNG, H-C. 2008. Migration and cultural interaction in southern coastal China, Taiwan and the northern Philippines, 3000 BC to AD 100: the early history of the Austronesian-speaking populations. Unpublished PhD dissertation, The Australian National University.

IA, CASS, ATGZ, Cultural Relic Survey Team of Guilin City \& Zengpiyan Site Museum 2003. Guilin Zengpiyan. Beijing: Wenwu (in Chinese).

IA, Hunan. 2000. Excavation of the Gaomiao site at Qiangyang in Hunan. Wenwu 4: 4-23 (in Chinese).

- 2006. Excavation of the Neolithic Gaomiao site, Hongjiang in Hunan. Kaogu 7: 9-15 (in Chinese).

JIAO, T.L. 1994. The prehistoric culture of the Lingnan region from the Late Pleistocene to Early Holocene. Kaogu Xuebao 1: 1-24 (in Chinese).

LIN, G.W. 2005. Neolithic culture of the Fujian coastal region, in Z.Y. Chen \& J.G. Pan (ed.) Archaeological seminar on the southeastern coastal islands of China: 75-90. Lienchiang: Cultural Affairs Bureau (in Chinese).

LIU, Y.C. \& S.Q. GUO. 2005. Status and meaning of Kinmen's Fuguodun in the southeastern coastal areas of China, in Z.Y. Chen \& J.G. Pan (ed.) Archaeological seminar on the southeastern coastal islands of China: 135-95. Liechiang: Cultural Affairs Bureau (in Chinese).

Lu, P. 2010. Zooarchaeological study on the shell middens in the Yong Valley of Guangxi. Unpublished PhD dissertation, IA of CASS, Beijing (in Chinese).

LU, T.L-D. 1999. The transition from foraging to farming in China. Bulletin of the Indo-Pacific Prehistory Association 18: 77-80.

-2007. Natural resources and subsistence strategies in prehistoric Hong Kong. Kaogu 6: 36-45 (in Chinese).

MA, J.X. 1988. Distribution characteristics of the ancient sites in the Sanxia region of the Yangtze River. Jianghan Kaogu 4: 115-19 (in Chinese).

Matsumura, H., M. Oxenham, Y. Dodo, K. DOMETT, K.T. NGuYen, L.C. NGUYEN, K.D. NguYen, D. Huffer \& M. Yamagata. 2008. Morphometric affinity of the late Neolithic human remains from Man Bac, Ninh Binh Province, Vietnam: key skeletons with which to debate the 'two layer' hypothesis. Anthropological Science 116(2): 135-48.

Matsumura, H., M. Oxenham, K.T. NGuyen, L.C. Nguyen \& K.D. Nguyen. 2011. Population history of mainland Southeast Asia: the two layer model in the context of northern Vietnam, in $\mathrm{N}$. Enfield \& J. White (ed.) Dynamics of human diversity: the case of mainland Southeast Asia: 1-23. Canberra: Pacific Linguistics.

(C) Antiquity Publications Ltd. 
MEACHAM, W. 1978. Sham Wan, Lamma Island: an archaeological site study (Journal monograph 3). Hong Kong: Hong Kong Archaeological Society.

NAKAMURA, S. 2000. The origin of Chinese rice cultivation. Chinese Archaeology 10: 1-11 (in Japanese).

Nishitani, M. 1997. The Neolithic in coastal southern China. Bulletin of the National Museum of the Japanese History 70: 1-56 (in Japanese).

NGUYEN, V. 2005. The Da But culture: evidence for cultural development in Vietnam during the Middle Holocene. Bulletin of the Indo-Pacific Prehistory Association 25: 89-93.

NGUYEN, W.H. 2006. Da But culture in Vietnam, in IA, CASS (ed.) Prehistoric archaeology of south China and Southeast Asia: 341-6. Beijing: Wenwu (in Chinese).

PEI, A.P. 1999. Xiantouling assemblage in the Zhujiang estuary. Dongnan Kaogu Yanjiu 2: 117-31 (in Chinese).

Shenzhen Institute of Cultural Relics and Archaeology Identification. 2006. 7000-year-old Neolithic site found at Xintouling in Shenzhen. China Cultural Relics News, 6 December 2006, p. 2 (in Chinese).

TANG, C. 1999. Archaeological reconstruction of the aboriginal culture in south China. Dongnan Kaogu Yanjiu 2: 83-9 (in Chinese).

WANG, H.G. 2006. New discoveries and new knowledge of Guizhou archaeology. Kaogu 8: 3-10 (in Chinese).

WANG, Y.P. 2005. Prehistoric cultural origin in China. Beijing: Science (in Chinese).

Wu, C.M. 1999. Local tradition and outside influence of the Mesolithic culture in south China, in Yingde City Museum, Department of Anthropology, Sun Yat-sen University and Guangdong Provincial Museum (ed.) Thesis collection of the Mesolithic culture and its related issues: 6-18. Guangdong: People Press (in Chinese).

YAN, W.M. 2002. The origins of rice agriculture, pottery and cities, in Y. Yoshinori (ed.) The origins of pottery and agriculture: 151-6. New Delhi: Roli Books.

YASUDA, Y. 2002. Origins of pottery and agriculture in East Asia, in Y. Yoshinori (ed.) The origins of pottery and agriculture: 119-42. New Delhi: Roli Books.
YUAN, J.R. 1991. Early Holocene cave sites in Dao county of Hunan and its related issues, in Fengkai County Museum, IA of Guangdong, Guangdong Provincial Museum \& Relics and Museum Association of Guangdong Province (ed.) Thesis collection in remembrance of the Huangyandong Cave being discovered for 30 years: 100-108. Guangdong: Travel and Tourism Press (in Chinese).

- 2000. The 10 000-year-old rice husks and potteries of the Yuchanyan Cave of Dao county in Hunan, in W.M. Yan \& Y. Yasuda (ed.) The origins of rice agriculture, pottery, and cities: 35. Beijing: Wenwu (in Chinese).

ZHANG, C. 1999. The excavations at Xianrendong and Diaotonghuan, Jiangxi. Bulletin of the Indo-Pacific Prehistory Association 18: 97-100.

-2000 . A brief review of the Early Neolithic culture of southern China, in Z.Y. Xu \& Z.P. Zhang (ed.) New century reflection and expectation of Chinese archaeology: 190-98. Beijing: Science (in Chinese).

- 2007. The early potteries of southern China, in Center for the Study of Chinese Archaeology et al. (ed.) Gudai Wenming [Ancient civilisation] 5: 1-16. Beijing: Wenwu (in Chinese).

- 2011. Cultural remains of the Jiahu phase I. Wenwu 3: 46-53 (in Chinese).

ZHANG, C. \& H-C. Hung. 2008. The Neolithic of southern China - origin, development and dispersal. Asian Perspectives 47(2): 299-329.

-2010 . The emergence of agriculture in southern China. Antiquity 84: 11-25.

ZHANG, W. X. 2000. Rice bi-peaked tubercles, the characteristics of ancient rice, and the origin of rice cultivation, in W.M. Yan \& Y. Yasuda (ed.) The origins of rice agriculture, pottery, and cities: 122 . Beijing: Wenwu (in Chinese).

ZhaO, C. H. \& X.H. Wu. 2003. The discovery and the related issues of Chinese early potteries, in School of Archaeology and Museology, Beijing University (ed.) Kaoguxue Yanjiu [Study of Archaeology] 5: 98-100. Beijing: Science (in Chinese).

ZhaO, Z. J., L.D. Lu \& X.G. Fu. 2005. The study of the excavated phytoliths in the Dingsishan site of Yongning County of Guangxi. Kaogu 11: 76-84 (in Chinese). 